\title{
Investigation of self healing behaviour of asphalt mixes using beam on elastic foundation setup
}

\author{
Jian Qiu • A. A. A. Molenaar • \\ M. F. C. van de Ven · Shaopeng Wu \\ Jianying Yu
}

Received: 17 January 2011 / Accepted: 18 October 2011/Published online: 10 November 2011

(C) The Author(s) 2011. This article is published with open access at Springerlink.com

\begin{abstract}
Self healing of asphalt mixes is known for more than four decades. However, it is a complex phenomenon which depends on the duration of the rest period, temperature, crack size, etc. In order to quantify the self healing behaviour of asphalt mixes, a test setup was proposed in this research using an asphalt beam on an elastic foundation. Within this setup, a notched asphalt beam was glued on a low modulus rubber foundation, and a symmetric monotonic load was applied with loading-unloading-healing-reloading cycles. The rubber foundation was used to avoid permanent deformation and to ensure a controllable healing process. Experimental results indicate that the beam on elastic foundation (BOEF) setup is capable for self healing investigations of asphalt mixes. The healing process was quantified by the recovery of the strength and the recovery of the crack opening displacement. The time, temperature and crack size dependency of the self healing behaviour were observed over the healing periods. Moreover, a self healing model was proposed to decompose
\end{abstract}

J. Qiu $(\bowtie)$ · A. A. A. Molenaar · M. F. C. van de Ven Road and Railway Engineering, Faculty of Civil Engineering and Goesciences, Delft University of Technology, 2600 GA Delft, The Netherlands e-mail: j.qiu@tudelft.nl; pidqiu@hotmail.com

J. Qiu · S. Wu · J. Yu

Key Laboratory of Silicate Materials Science and Engineering of Ministry of Education, Wuhan University of Technology, Wuhan 430070, China the self healing phenomenon observed in the BOEF healing tests. It is shown that at the beginning of the healing period the delayed visco-elastic healing is the main reason of the recovery of the crack opening displacement and the viscous healing is important for healing after longer time/higher temperature.

Keywords Healing - Asphalt · Elastic foundation . Strength $\cdot$ Rest periods

\section{Introduction}

Self healing of bituminous materials has been a hot topic for over 40 years. One of the first notifications of healing was made in the 1960 s by Bazin [1]. Healing is defined as a recovery of the stiffness and strength of bituminous materials, which suffered from damage, during rest periods and high temperatures. Till now, many contributions have been made to identify and model this phenomenon by means of different approaches and different levels of complexity ranging from molecular level till pavement level [2-17]. For details of these approaches the reader is referred to the literature review made by Qiu [18].

Healing is a complex phenomenon, which is highly dependent on the rest time between two load pulses, temperature, crack phase and material type. According to the author of this paper, the healing phenomenon of bituminous materials is believed to be composed of 
two major parts: visco-elastic healing and viscous healing [17]. Visco-elastic healing is related to the delayed elastic recovery behaviour of bituminous materials, while the viscous healing is related to the viscosity of bituminous materials. It was also observed that visco-elastic healing happens much faster than viscous healing.

Hence, it would be interesting to quantify the healing phenomenon in asphalt mixes and to decompose this phenomenon into two healing components.

A test setup named beam on elastic foundation (BOEF) has been in use for almost 40 years for evaluation of cracks propagating through asphalt mixes $[19,20]$. The intention of this setup, in which an asphalt beam is supported by an elastic foundation, is to simulate a real flexible pavement structure. In this study, the BOEF test setup is proposed for cracking and healing investigations of asphalt mixes.

\section{Background of BOEF setup}

Firstly, the BOEF test was used for fatigue characterisation of asphalt mixes. Upon using a soft art gum rubber foundation, Majidzadeh found that the creep effect of an asphalt beam under load repetitions can be neglected $[19,21]$. With respect to the fatigue crack growth, the parameter $\mathrm{n}$ of Paris's law obtained from the BOEF fatigue test was around 3.7. This was in agreement with what was expected from theory [20].

In addition, Molenaar and Thewessen investigated the fatigue behaviour of asphalt beams with full contact between asphalt beam and rubber foundation [20]. They concluded that the asphalt beam should be glued on the rubber foundation in order to simulate full contact and full friction. When no glue was used, partial slip could occur between the beam and the rubber. Due to the full contact, the crack propagation speed under a symmetric load decreased strongly when the crack length reached about $60 \%$ of the height of the beam; then the crack entered the compression zone and no further propagation was observed.

Furthermore, the BOEF test was also used for reflective cracking analysis. Molenaar investigated the effect of the stress absorbing membrane interlayers (SAMI) with the BOEF tests [22]. Within the test, both vertical deflection and horizontal tensile displacements were monitored. A special clamp with a strain gauge was developed to monitor the vertical crack propagation. It was observed that the crack was retarded by using the SAMI. A similar setup was adopted successfully by Brown [23] and Rowe [24] for characterizing the reinforcing interlayer materials.

Roesler and Gaedicke applied the BOEF setup for concrete crack investigation [25-27]. A pre-notched concrete slab was placed on a clay subgrade. Post-peak loading-unloading-reloading cycles were used to investigate the failure envelope of concrete materials by means of a load-crack opening displacement (COD) curve. When the results of the BOEF tests were compared with the results of the simply supported beams, the maximum load of the BOEF beam was observed to be higher because of the presence of the elastic foundation. Another interesting observation was that after a certain crack opening, the load increased again, which may be due to the load transfer through the elastic foundation.

As shown from literature, it is foreseen that the BOEF setup is useful for cracking and healing investigation because of the following reasons: (a) the elastic foundation absorbs most of the deformation, which helps for healing investigations and eliminating the influence of permanent deformation; (b) After a loading-unloading cycle, the elastic foundation will help to close the crack during unloading thus to support the healing process of the asphalt mixes. Hence, the BOEF setup is chosen for cracking and healing investigation of asphalt mixes in this study.

\section{Experimental}

\subsection{Materials}

\subsubsection{Asphalt mixes}

A dense asphalt mix type DAC $0 / 8$ was used in this study. The target air voids content was $4 \%$. Figure 1 shows the gradation curve of this asphalt mix which is in accordance with the Dutch specifications. Information of the materials used is given in Table 1.

The asphalt mixes were compacted using a PresBox shear box compactor into a block with a size of $150 \mathrm{~mm} \times 175 \mathrm{~mm} \times 450 \mathrm{~mm}$ [28]. Then the BOEF beams in size of $35 \mathrm{~mm} \times 70 \mathrm{~mm} \times 400 \mathrm{~mm}$ were sawed. A small notch was sawed in the middle of the beam with $3.5 \mathrm{~mm}$ in width and $15 \mathrm{~mm}$ in depth. 


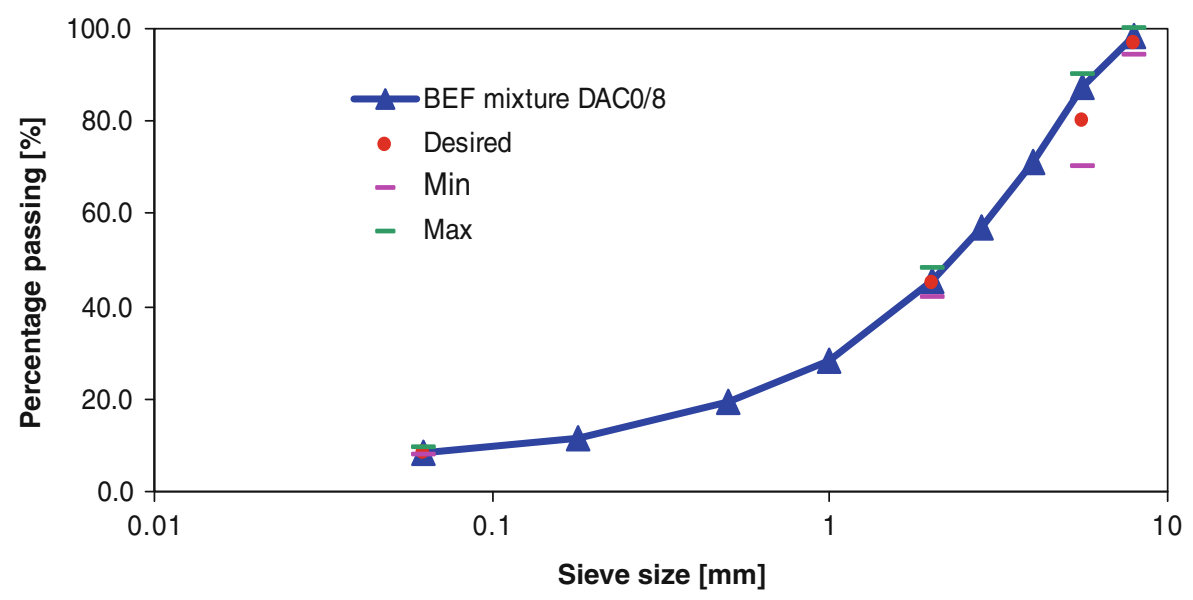

Fig. 1 Gradation curve of DAC 0/8 asphalt mixes

Table 1 List of materials used in DAC 0/8 asphalt mixes

\begin{tabular}{llllllll}
\hline Materials & $\begin{array}{l}\text { Scottish stone } \\
8-5.6 \mathrm{~mm}\end{array}$ & $\begin{array}{l}\text { Scottish stone } \\
5.6-4 \mathrm{~mm}\end{array}$ & $\begin{array}{l}\text { Norwegian stone } \\
6-2 \mathrm{~mm}\end{array}$ & $\begin{array}{l}\text { Crashed sand } \\
2-1 \mathrm{~mm}\end{array}$ & $\begin{array}{l}\text { Crashed sand } \\
1-0 \mathrm{~mm}\end{array}$ & $\begin{array}{l}\text { Wigro } \\
\text { filler }\end{array}$ & $\begin{array}{l}70 / 100 \text { Penetration } \\
\text { bitumen }\end{array}$ \\
\hline Proportions $(\%)$ & 11.2 & 19.6 & 21.5 & 16.8 & 16.8 & 7.5 & 6.5 \\
Density $\left(\mathrm{g} / \mathrm{mm}^{3}\right)$ & 2.5758 & 2.5758 & 2.6433 & 2.677 & 2.677 & 2.750 & 1.025 \\
\hline
\end{tabular}

\subsubsection{Rubber}

A Neopreen rubber was selected as the elastic foundation (Fig. 2a), with a hardness of $40^{\circ}$ shore and a thickness of $20 \mathrm{~mm}$. The Young's modulus was 6.5 MPa and Poisson's ratio was 0.5. Another piece of rubber with a size of $20 \mathrm{~mm} \times 10 \mathrm{~mm} \times 35 \mathrm{~mm}$ with a Young's modulus of $15 \mathrm{MPa}$ and Poisson's ratio of 0.5 was used as a loading pad.

\subsubsection{Others}

A steel plate with a thickness of $10 \mathrm{~mm}$ was used as foundation (Fig. 2a). A Rengel SW 404 glue was selected for its excellent workability on adhesion of asphalt-rubber and rubber-steel.

A Canon G11 camera with a remote control was used for monitoring the crack propagation in the asphalt beam. A white paint was used to make the cracks visible. A ruler marker with 5, 10 and $20 \mathrm{~mm}$ in length was used to quantify the crack length on the photos.

\subsection{BOEF test setup}

Figure 2a shows the BOEF setup developed in this study. In order to ensure the full contact between the asphalt beam and the rubber foundation, the asphalt beam was fully glued on the rubber except $10 \mathrm{~mm}$ away from each side of the notch. In addition, the rubber-steel interface was also fully glued.

A load was applied in the middle of the beam through a rubber pad. Three displacement values were obtained throughout the test: the vertical displacement, VD; the crack opening displacement, COD, which was located right under the crack tip with a measure distance of $20 \mathrm{~mm}$; and the side displacement, SD, which was located $10 \mathrm{~mm}$ away from the edge of the beam.

\subsection{BOEF test procedure}

\subsubsection{MBT}

In order to analyze the crack behaviour of the asphalt beams, a monotonic BOEF test procedure (MBT) was first conducted (Fig. 2b). The test was done at $5^{\circ} \mathrm{C}$. During the MBT, a COD controlled loading was applied with a constant COD speed of 0.001 and $0.002 \mathrm{~mm} / \mathrm{s}$. During the test, different displacement signals were measured as shown in Fig. 2a, including the crack opening displacement COD as control, the vertical displacement (VD) and the side displacement (SD). 

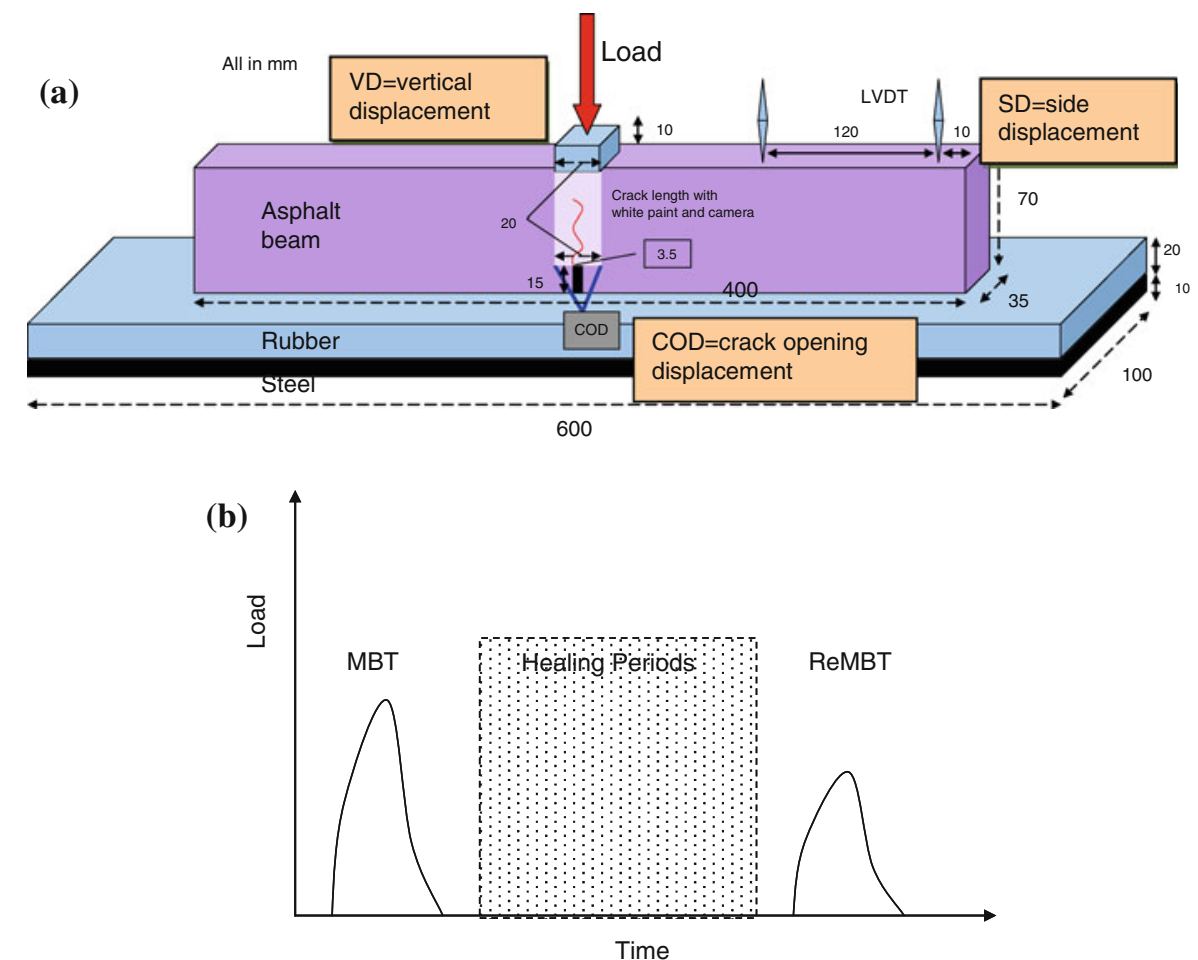

Fig. 2 a BOEF setup, and $\mathbf{b}$ test procedures

\subsubsection{ReMBT}

A COD controlled loading with a COD speed of $0.001 \mathrm{~mm} / \mathrm{s}$ was applied till target CODs, which were $0.2,0.6$ and $0.9 \mathrm{~mm}$. Then an unloading phase was applied at a COD speed of $-0.001 \mathrm{~mm} / \mathrm{s}$. When the load level had returned to 0 , the external load was removed. A rest time of $1 \mathrm{~h}$ was first applied at $5^{\circ} \mathrm{C}$. Then healing periods of 3 and $24 \mathrm{~h}$ and healing temperatures of 5 and $40^{\circ} \mathrm{C}$ were applied. After healing, the samples were again conditioned at $5^{\circ} \mathrm{C}$ for at least $2 \mathrm{~h}$. A COD controlled reloading called ReMBT was applied with a COD speed of $0.001 \mathrm{~mm} / \mathrm{s}$ till a COD value of $1.5 \mathrm{~mm}$ was obtained. For comparison purpose, an immediate reloading (or with the representation of $0 \mathrm{~h}$ reloading) test was also applied after the previous load had returned to 0 .

\section{Cracking of asphalt mixes}

Figure 3 shows the MBT test results for different samples as well as different COD speeds. At a COD level of around $0.2 \mathrm{~mm}$, the slope of the load-COD curve decreases, and this may be seen as the start of cracking. When comparing the different COD speeds, a higher COD speed shows a higher load value where the slope of the load-COD curves decreases. However, the differences in different COD speeds are not so evident when the repeatability of the tests is considered.

Figure 4 shows an example of the measured VD and SD during the MBT test. The development of the $\mathrm{VD}$ is nonlinear. When comparing the VD-COD curve with the load-COD curve which is shown in Fig. 3, a similar trend can be observed.

In addition, the development of the SD shows different phases. Please note that a positive value of the SD means that the side of the beam is moving downwards, and a negative value means that the side of the beam is moving upwards. The SD shows a slightly increase at the beginning of the test until a COD level of $0.02 \mathrm{~mm}$. This implies that at the beginning the whole beam moves downwards. Then, the SD starts to decrease linearly with the increasing COD, which means the beam starts to bend. After a certain moment, the rate at which the SD decreases, 
Fig. 3 MBT test results

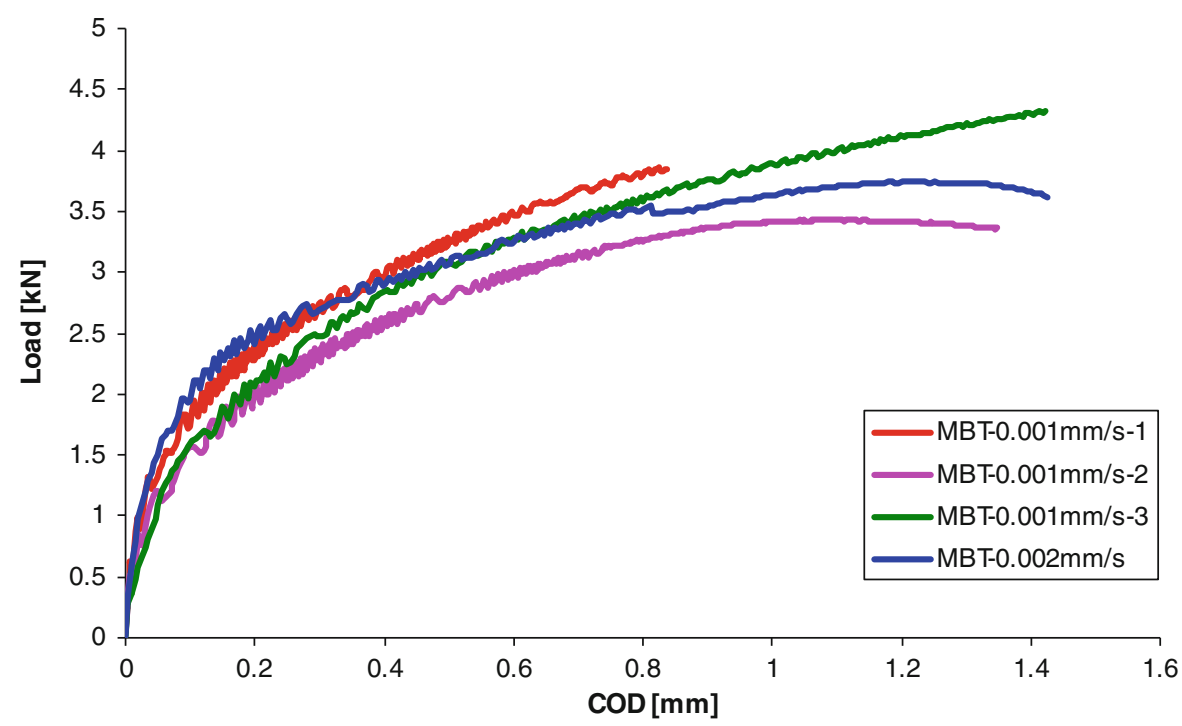

implying that a non-linear second phase has started (see Fig. 4). It is believed that the start of this second phase in the SD curve marks the initiation of cracking. Interestingly, the start of the second phase also correlates with the change of the slope of the loadCOD curve and the change of the slope of the VD-COD curve.

In order to determine the crack propagation speed, a camera assisted crack length measurement was applied. Figure 5a shows an example of the development of the crack length at different COD values.
Figure $5 \mathrm{~b}$ shows the development of the vertical crack length (CL) for different samples and different COD speeds. The CL grows with the development of the COD. No visible CL can be observed at the COD values of $0-0.2 \mathrm{~mm}$. The development of the CL slows down in the end because the crack approaches the compression zone of the BOEF asphalt beam; this slows down or even stops the crack propagation. At a COD speed of $0.002 \mathrm{~mm} / \mathrm{s}$ a higher CL developing speed and a higher final CL was observed.

From the MBT results, the following cracking phases during the growth of the COD can be observed:

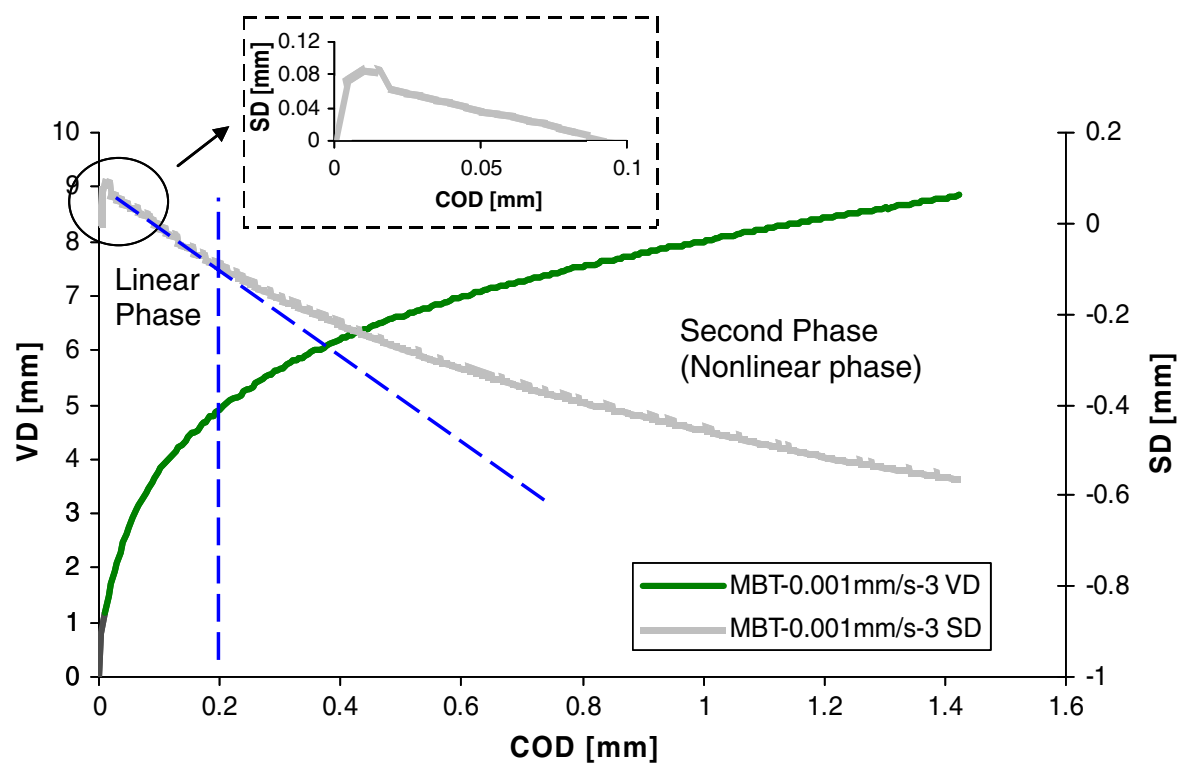

Fig. 4 Developments of the VD and the SD for a COD speed of $0.001 \mathrm{~mm} / \mathrm{s}$ 
a. Preloading phase (about $0-0.02 \mathrm{~mm}$ COD): the BOEF setup is under compression due to the low stiffness of the rubber foundation.

b. No visible crack phase (about $0.02-0.2 \mathrm{~mm}$ COD): the BOEF beam is bending. However, due to the visco-elastic effect, no visible crack can be observed.

c. Crack propagation phase (about $0.2-1 \mathrm{~mm}$ COD): the crack develops fast with the increase of the COD. The side displacement, SD, enters the nonlinear second phase.

d. Crack propagation phase in compression zone $(\mathrm{COD} \geq 1 \mathrm{~mm})$ : the crack propagation speed slows down with the increasing COD.

Since the healing behaviour might be dependent on the amount of damage, healing tests were carried out on specimens which were cracked to different COD levels. As a result, three COD levels were selected to which specimens were loaded and subjected to a healing period afterwards. The three selected COD levels are 0.2, 0.6 and $0.9 \mathrm{~mm}$. The related crack lengths are no visible crack, $3-5 \mathrm{~mm}$ and $8-10 \mathrm{~mm}$, respectively.

\section{Healing of asphalt mixes}

Figure 6 shows the loading-reloading curves with various healing conditions. The following can be observed from the test results:

- The loading and unloading paths of all the BOEF specimens are almost the same. The reloading curves show the same trend as the loading curves, but with lower values. It seems that the loadingunloading-reloading cycles form a failure envelope of the load-COD curve. Details of this envelope behaviour will be discussed in Sect. 5.1.

- The reloading curves show different slopes at different healing periods. It seems that the immediate reloading shows the highest slope. Then the (a)

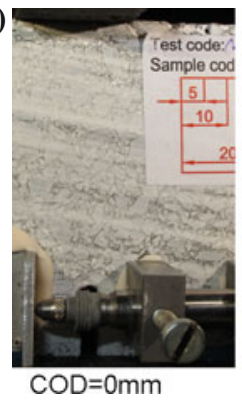

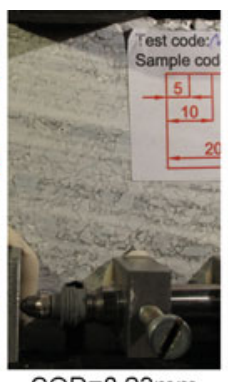

$\mathrm{COD}=0.23 \mathrm{~mm}$

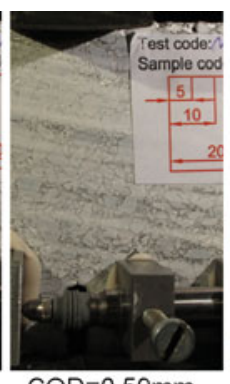

$\mathrm{COD}=0.59 \mathrm{~mm}$

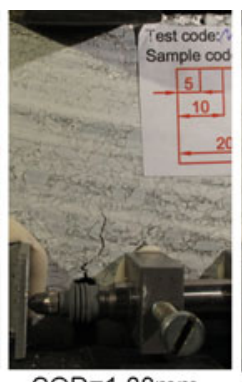

$\mathrm{COD}=1.08 \mathrm{~mm}$

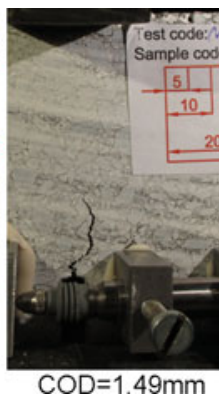

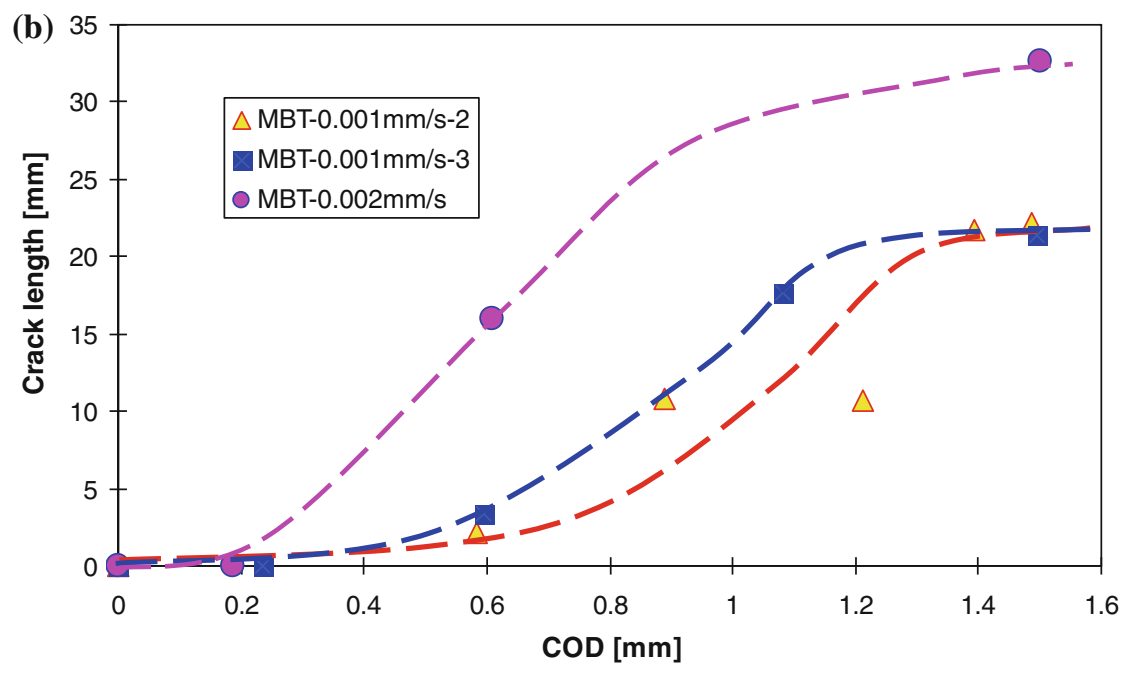

Fig. 5 a Crack length measurements for a MBT sample, and, b Crack length developments during the MBT tests 
Fig. 6 BOEF healing results at the COD level of a $0.2 \mathrm{~mm}$, b $0.6 \mathrm{~mm}$, and, c $0.9 \mathrm{~mm}$
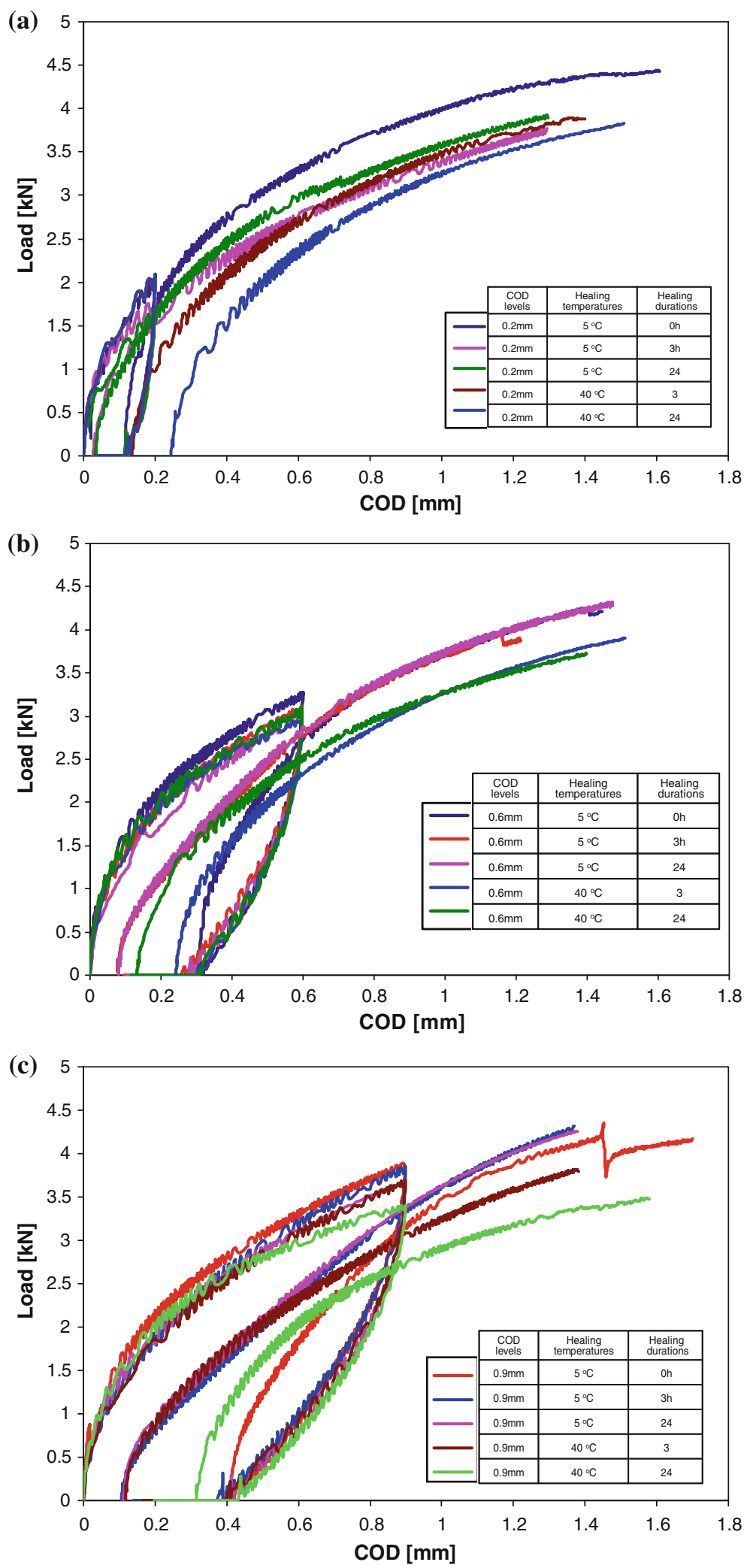
slope decreases to the lowest level after short periods of healing. Given enough time, the slope increases slowly with the increase of healing time and healing temperature. The change in the reloading curves will be discussed in detail in Sect. 5.2.

- When comparing the transition load, which corresponds to the load value where the phase change from the no visible crack phase to the crack propagation phase of the load-COD curve, it appears that the highest value is obtained from the immediate reloading, and the lowest value from a short period of healing. Then the transition load increases again with the increase of healing time and healing temperature. Details of the change in the transition load will be discussed in Sect. 5.3.

- During healing periods, a continuous decrease of the COD can be observed at $5^{\circ} \mathrm{C}$. The development of the COD will be discussed in detail in Sect. 5.4.

\subsection{Failure envelope}

Figure 7 illustrates the results of reloading without application of a rest period for different target CODs. An MBT test to failure result is also presented. It can be seen that all loading-reloading curves are within the MBT curve. The MBT curve can be seen as a failure envelope for the loading-reloading curves. In addition, it appears that after the reloading cycle, the curve will not return to the same point of the loading curve where it unloaded from, but to a point which belongs to a lower load value. This difference increases with the increase of the target COD level applied. This phenomenon is due to the damage which caused in such an unloading-reloading loop [29]. In this study, the loading-unloading envelope is used as an indicator of samples with no healing (immediate reloading) and as a comparison for the healing samples.

\subsection{Reloading curve}

Figure 8 compares the reloading curves with different healing conditions at different COD levels of 0.2, 0.6 and $0.9 \mathrm{~mm}$, respectively. The following can be observed from the test results:

- All the reloading curves show similar trend. All of the reloading curves are within the MBT loading curve except the $0 \mathrm{~h}$ reloading curve, which shows even higher value when compared to the loading curve. The reason could be the residual compressive stress which develops in the BOEF sample after unloading and the high confining force from the rubber foundation. Both factors result in a higher load needed to get a certain crack opening displacement and to get failure. It should be noted that the compressive residual stress will not be

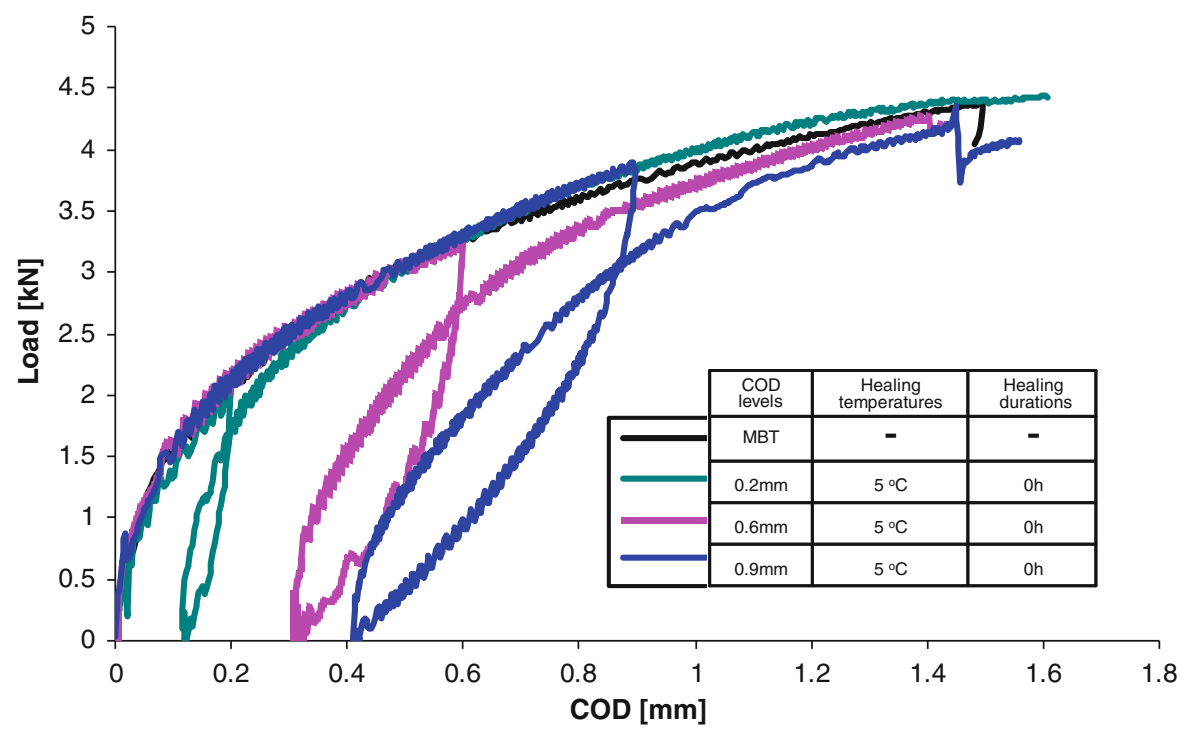

Fig. 7 Illustration of the BOEF envelopes 
Fig. 8 Comparison of the ReMBT curves at the COD level of a $0.2 \mathrm{~mm}$

b $0.6 \mathrm{~mm}$, and, c $0.9 \mathrm{~mm}$
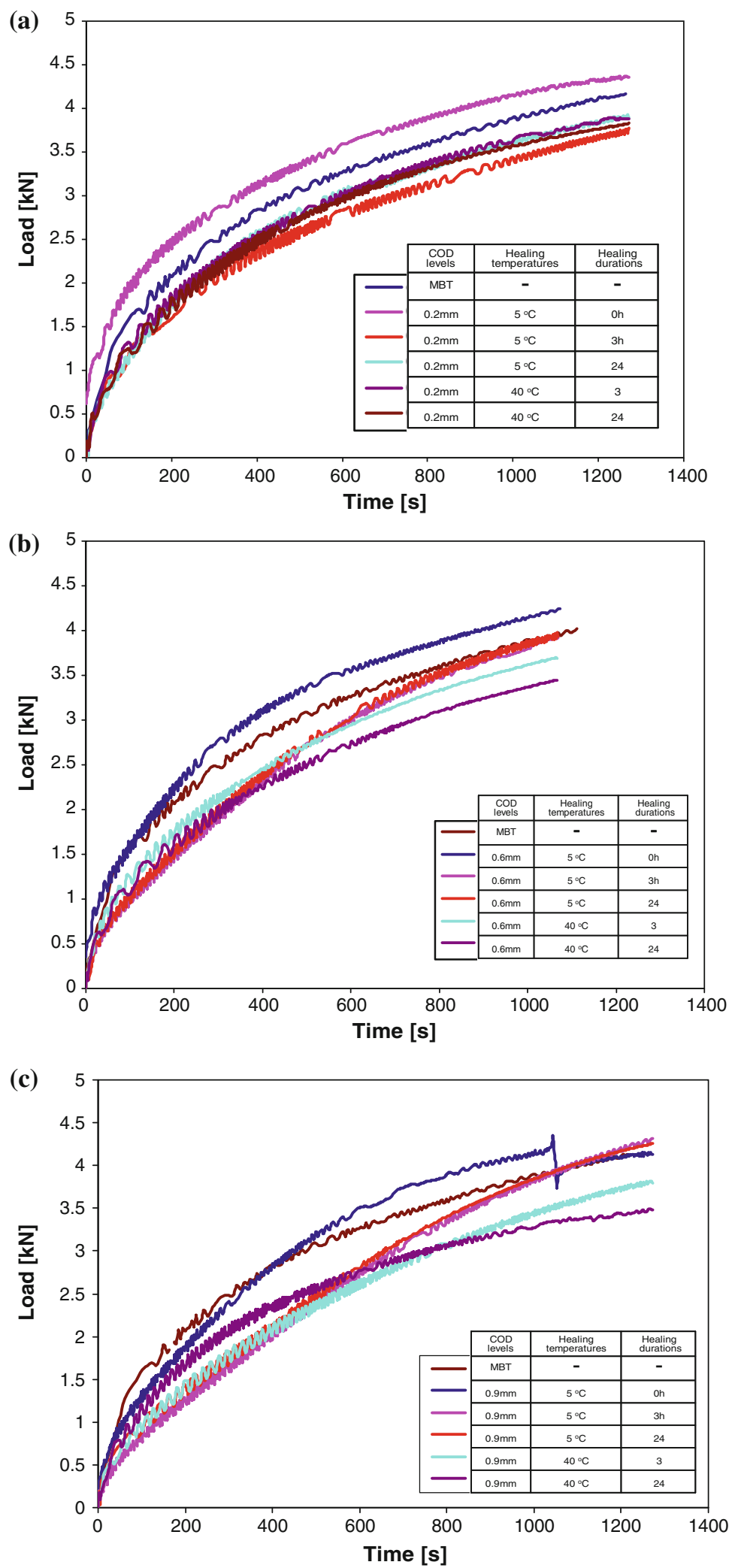
present any more after a certain period of time because of relaxation.

- The slope of the curve decreases when reloading is applied after a short healing period of $3 \mathrm{~h}$ at $5^{\circ} \mathrm{C}$. This may be due to the release of the residual compressive stress of the BOEF setup due to relaxation as explained above. This trend is the same among all the target COD levels.

- When comparing the curves with different healing conditions despite the $0 \mathrm{~h}$ reloading, a slightly increase of the load-COD curve is noticed with the increase of healing time and healing temperature.

- When comparing the healing temperatures, a higher temperature does play a role in the increase of the slope in the beginning. A slope decrease in further development of the reloading curve is also observed.

- When comparing the reloading curves obtained at the three cracking phases, a reloading of a smaller target COD level shows a higher slope in the beginning.

\subsection{BOEF strength}

In order to further investigate the healing behaviour of asphalt beams with the BOEF test setup, a parameter called the BOEF strength, $S_{\mathrm{BOEF}}$, was introduced. Figure 9 shows the determination of the $S_{\mathrm{BOEF}}$. The BOEF strength was defined as the transition load from the no visible crack phase to the crack propagation phase. The load value corresponding to the linearnonlinear transition of the SD-COD curve has been used to quantify this transition load. It should be noted that this strength is not exactly the strength of the asphalt beam. It represents the load needed for the whole BOEF setup to start a crack. The $S_{\mathrm{BOEF}}$ is a combination of the strength of the beam and the reaction load from the rubber foundation.

Table 2 lists all the measured $S_{\mathrm{BOEF}}$. However, when determining the $S_{\mathrm{BOEF}}$ of the loading curves of the COD level of $0.2 \mathrm{~mm}$, the SD-COD change is still in the linear range. So the maximum load value of the load-COD curve was used.

Figure 10 shows the BOEF reloading strength percentages for different healing conditions. The BOEF reloading strength percentage is defined by the BOEF reloading strength divided by the BOEF loading strength. The following can be observed from the results:

- The loading strengths of all the beams are almost constant. An average value around $2.1 \mathrm{kN}$ is obtained.

- The $S_{\text {BOEF }}$ at $0 \mathrm{~h}$ reloading is higher than the loading strength, which may be due to the residual stresses and the contribution of the rubber foundation as explained before.

- The reloading strength percentages at the COD level of $0.2 \mathrm{~mm}$ shows all high values above $100 \%$, notably because the SD-COD curve is still linear during loading. So the reloading percentage is overestimated. At the COD level of $0.2 \mathrm{~mm}$, almost no change of the BOEF strength can be observed during healing periods. It seems that during unloading of this COD level, the no visible crack heals immediately.
Fig. 9 Definition of the BOEF strength $S_{\text {BOEF }}$

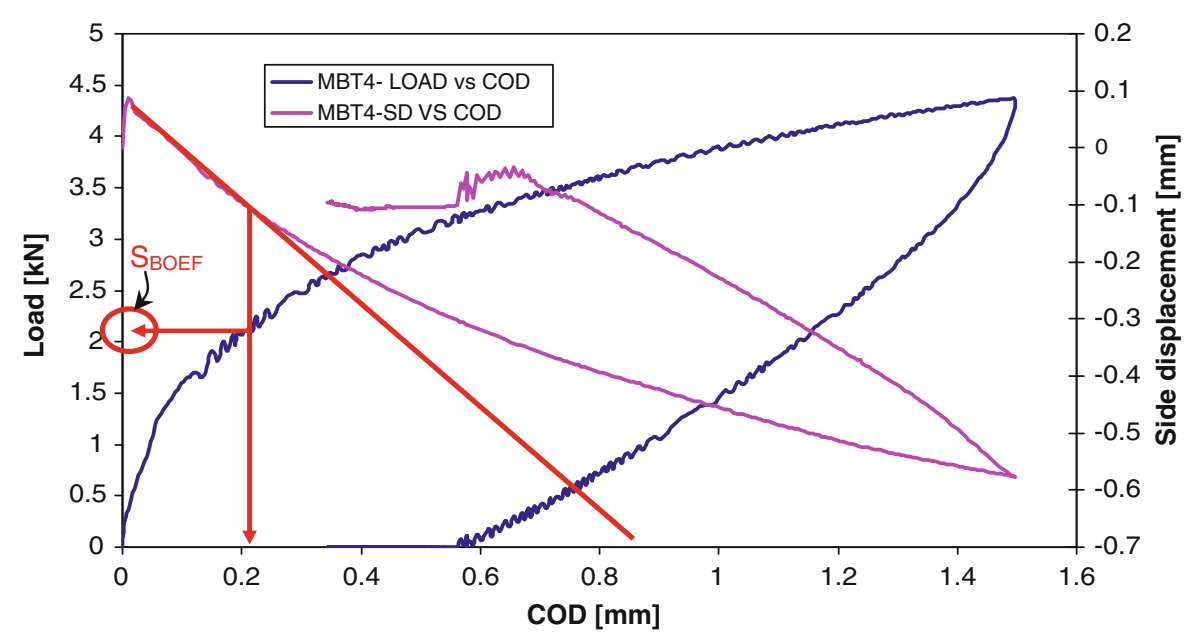


Table 2 List of the BOEF strength results

\begin{tabular}{|c|c|c|c|c|c|}
\hline & $0 \mathrm{~h} @ 5^{\circ} \mathrm{C}$ & $3 \mathrm{~h} @ 5^{\circ} \mathrm{C}$ & $24 \mathrm{~h} @ 5^{\circ} \mathrm{C}$ & $3 \mathrm{~h} @ 40^{\circ} \mathrm{C}$ & $24 \mathrm{~h} @ 40^{\circ} \mathrm{C}$ \\
\hline \multicolumn{6}{|l|}{$0.2 \mathrm{~mm}$} \\
\hline Loading strength (kN) & 2.1 & 1.7 & 1.7 & 2.0 & 2.0 \\
\hline Reloading strength (kN) & 2.7 & 2.3 & 2.2 & 2.5 & 1.7 \\
\hline Reloading percentage $(\%)$ & 128.0 & 134.7 & 133.3 & 125.3 & 85.3 \\
\hline \multicolumn{6}{|l|}{$0.6 \mathrm{~mm}$} \\
\hline Loading strength $(\mathrm{kN})$ & 2.5 & 2.2 & 2.5 & 1.8 & 2.2 \\
\hline Reloading strength (kN) & 3.2 & 1.5 & 2 & 1.6 & 2.1 \\
\hline Reloading percentage $(\%)$ & 128.0 & 68.2 & 80.0 & 88.9 & 95.5 \\
\hline \multicolumn{6}{|l|}{$0.9 \mathrm{~mm}$} \\
\hline Loading strength (kN) & 2.2 & 1.7 & 2.2 & 2.3 & 2.2 \\
\hline Reloading strength $(\mathrm{kN})$ & 3.0 & 0.9 & 1.4 & 1.7 & 1.8 \\
\hline Reloading percentage $(\%)$ & 136.4 & 52.9 & 64.8 & 73.9 & 80.5 \\
\hline
\end{tabular}

Fig. 10 Comparison of the BOEF strength percentages under different healing conditions

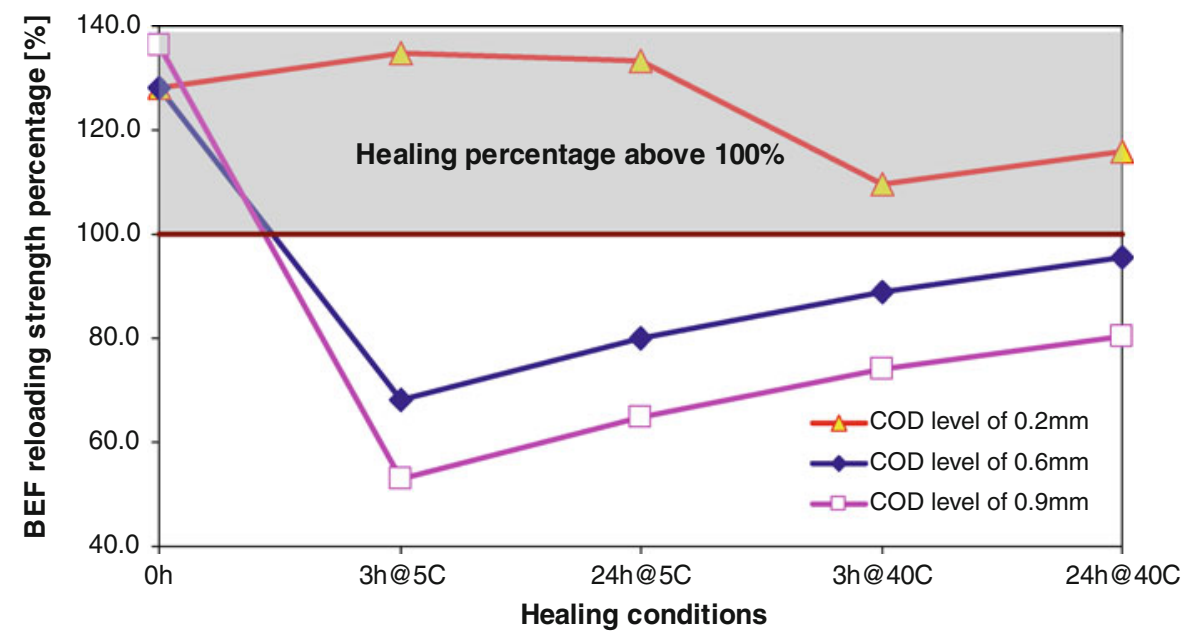

- At the COD levels of 0.6 and $0.9 \mathrm{~mm}$, all the reloading strengths are less when compared with the loading strength, except the $0 \mathrm{~h}$ value. An increase of the reloading strength percentage due to different healing conditions can also be observed except the $0 \mathrm{~h}$ value. The reloading strength recovers slightly faster at the COD level of $0.6 \mathrm{~mm}$ than the COD level of $0.9 \mathrm{~mm}$ which has more damage.

\subsection{Residual COD}

Figure 11 shows an example of the COD development during the BOEF test. The development of the COD during the healing period is a very interesting phenomenon. It can be seen that most of the COD recovery happens in the first hours.

Figure 12 shows the COD development at different healing conditions. The following can be observed:

- The residual COD decreases in all case during healing. However, an almost constant residual COD can be seen after $3 \mathrm{~h}$ healing at $5^{\circ} \mathrm{C}$ with the values ranging from 0.03 to $0.11 \mathrm{~mm}$. This can be due to mismatch of the crack faces at either side of the crack and/or deformation occurred in the asphalt beam because of the visco-elastic effect.

- When comparing the different target COD levels, a higher target COD value shows a higher residual COD. However, a higher target COD level shows a faster COD decreasing speed, which may be due to 


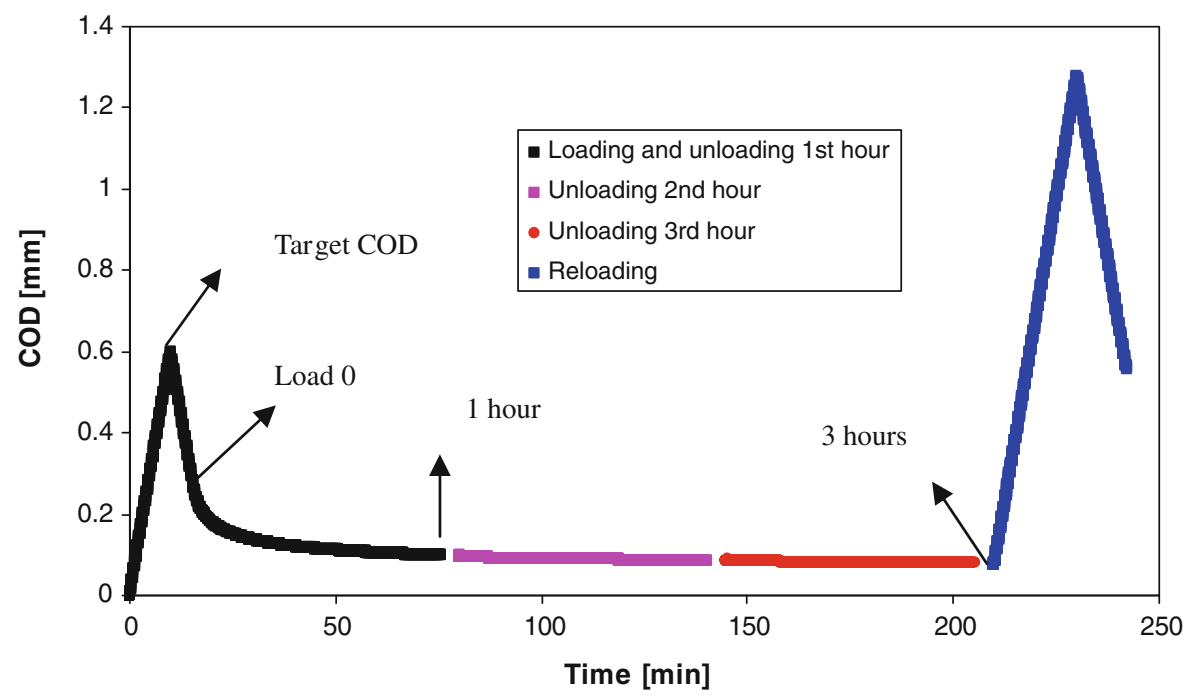

Fig. 11 Example of the COD development during the BOEF test (COD level of $0.6 \mathrm{~mm}$ and healing duration of $3 \mathrm{~h}$ at $5^{\circ} \mathrm{C}$ )

Fig. 12 COD development at different healing conditions

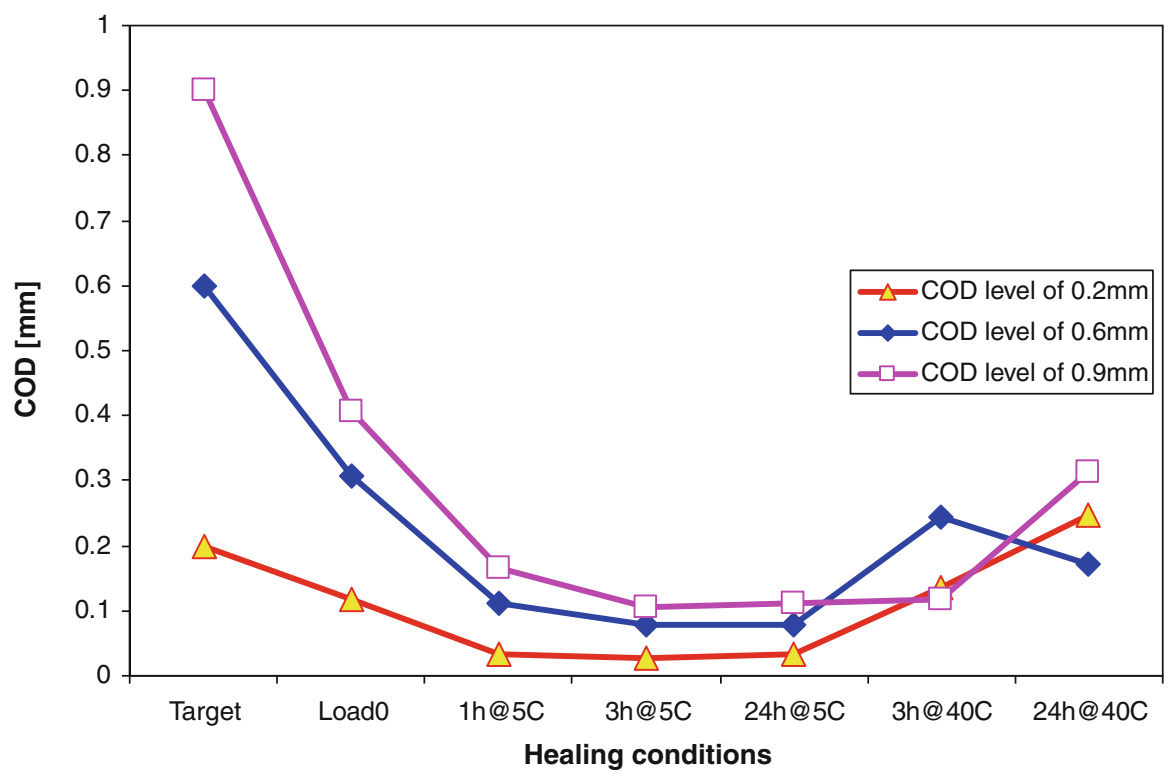

with the permanent deformation which can be observed during the mechanical loading of a simple supported beam at a constant test temperature. So the BOEF setup is unable to eliminate this deformation.

\subsection{Healing decomposition}

Figure 13 shows the decomposition of the healing components of an asphalt mix. It should be noted that visco-elastic behaviour. It should be noted that this thermal deformation is different when compared
- When the BOEF asphalt beam subjecting to a healing temperature of $40^{\circ} \mathrm{C}$, the residual COD increases. It is believed that the increase of the residual $\mathrm{COD}$ is caused by the artefact of the thermal cycles $\left(5-40-5^{\circ} \mathrm{C}\right)$ applied to the BOEF setup. The thermal cycles cause some thermal deformation of the asphalt beam because of the 
Fig. 13 Illustration of healing components decomposition

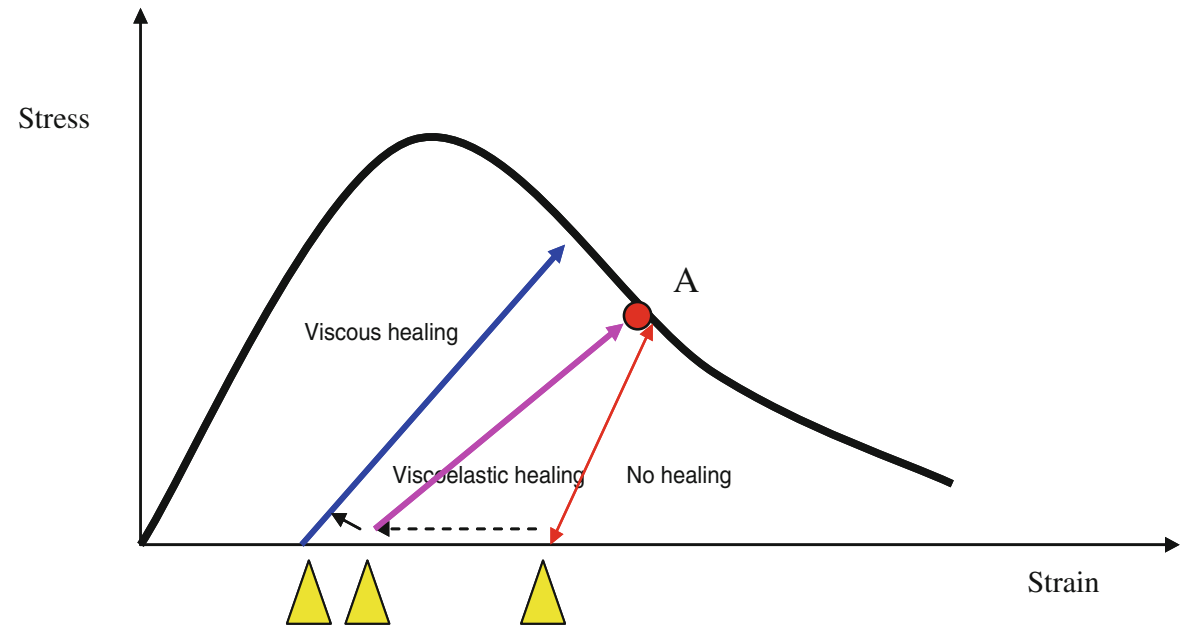

the stress-strain curve of an asphalt mix is very different when compared to the load-COD curve of the BOEF setup as it is shown in Fig. 3. As it is indicated from Roesler and Gaedicke, the load-COD curve of the BOEF setup can be seen as a system response instead of a material response of an asphalt mix [25-27]. In order to clarify the healing effect, the material response of an asphalt mix is discussed with a stress-strain relationship and the explanation is given as follows.

- In principle, if the reloading is applied immediately after the previous load returns to zero, the reloading curve should follow the unloading path to the point $\mathrm{A}$ on the failure envelope and should then follow the failure envelope. In this case no healing has occurred.

- If the reloading is applied after some time, then this time period allows visco-elastic healing to happen, which is mainly driven by the releasing of the residual stresses and delayed elastic recovery. This results in a lower residual strain value. However, the reloading curve should go through the point A which is the condition from where it was unloaded from.

- Furthermore, if the reloading is applied after healing at sufficient time and/or sufficient high temperature, the reloading curve would show an increase in the reloading strength because of the viscous healing due to flow, wetting and diffusion [9].

Combining the results obtained from the developments of both the BOEF strength and the residual COD in this test, one can conclude that the mentioned influencing factors are: a visco-elastic healing component and a viscous healing component. Viscoelastic healing happens in the first $3 \mathrm{~h}$ with a rapid recovery of the residual COD. Viscous healing happens after the visco-elastic healing with a clearly time-temperature dependency of the BOEF strength. However, it should be noted again that the BOEF strength is not a material strength parameter. Further investigation is needed to decompose the BOEF strength into material strength and response of the rubber foundation.

\section{Conclusions}

The cracking and healing behaviour of an asphalt mix were investigated with a beam on elastic foundation test setup. Based on the test data and analysis, the following can be concluded:

- The cracking behaviour of an asphalt mix tested by means of the BOEF setup can be investigated with the load-COD curve and the camera assisted crack length measurements. At a constant COD development speed of $0.001 \mathrm{~mm} / \mathrm{s}$, four phases can be observed: preloading phase, no visible crack phase, crack propagation phase and crack propagation phase in compression zone.

- The healing behaviour of an asphalt mix was investigated at COD levels of $0.2,0.6$ and $0.9 \mathrm{~mm}$, corresponding to crack lengths of no visible crack, $3-5 \mathrm{~mm}$ and $8-10 \mathrm{~mm}$, respectively. Certain healing times and temperatures were applied to the test setup. After a healing period, a reloading 
was applied as an indicator of healing. The time, temperature and crack size dependency could clearly be observed during the test.

- A BOEF strength value was introduced as a healing indicator. An increase in the BOEF strength can be observed with an increase in healing durations and/or healing temperatures. A recovery of the residual COD can also be observed as another healing indicator, which shows a fast recovery in a short healing period of $3 \mathrm{~h}$.

- A healing decomposition was proposed to explain the healing phenomenon of asphalt mixes. Healing is believed to be the combining effects of viscoelastic recovery and viscous flow. At the beginning, healing happens due to visco-elastic recovery, resulting in the recovery of the residual COD. If different healing times and temperatures are given, healing is contributed by viscous effect; this is mainly a flow driven process.

Research is ongoing to separate the behaviour of asphalt mixes and rubber foundation from the overall behaviour observed during the BOEF test. By doing this, more fundamental information concerning the cracking and healing behaviour of asphalt mixes will be obtained.

Acknowledgments The first author would like to thank the China Scholarship Council for the financial contribution. The authors appreciate the cooperation between Wuhan University of Technology and Delft University of Technology and express their wish to prolong and strengthen the current cooperation between the mentioned institutes of technology. Discussions and suggestions offered from Dr. Liantong Mo, Mr. Ad Pronk and Mr. Milliyon Woldekidan are highly appreciated.

Open Access This article is distributed under the terms of the Creative Commons Attribution Noncommercial License which permits any noncommercial use, distribution, and reproduction in any medium, provided the original author(s) and source are credited.

\section{References}

1. Bazin P, Saunier JB (1967) Deformability, fatigue and healing properties of asphalt mixes. Paper presented at the proceedings of the second international conference on the structural design of asphalt pavements. Ann Arbor, Michigan, USA

2. Qiu J, Van de Ven MFC, Wu SP, Yu JY, Molenaar AAA (2011) Fracture and healing capability of bituminous mastics. Experimental Mechanics, EXME1275, under review. Delft University of Technology
3. Qiu J, van de Ven MFC, Wu SP, Yu JY, Molenaar AAA (2011) Investigating self healing behaviour of pure bitumen using Dynamic Shear Rheometer. Fuel 90(8): 2710-2720

4. Van Dijk W, Moreaud H, Quedeville A, Uge P (1972) The fatigue of bitumen and bituminous mixes. Paper presented at the 3rd international conference on the structural design of asphalt pavements. Ann Arbor, Michigan, USA

5. Raithby KD, Sterling AB (1970) The effect of rest periods on the fatigue performance of a hot-rolled asphalt under repeated loading. J Assoc Asph Paving Technol 39:134-152

6. Francken L (1979) Fatigue performance of a bituminous road mix under realistic best conditions. Transp Res Rec 712:30-34

7. Lytton RL, Chen CW, Little DN (1998) Fundamental properties of asphalts and modified asphalts_task K: microdamage healing in asphalt and asphalt concrete. FHWA Final Report DTFH61-92-C-00170, vol 3

8. Lu X, Soenen, H., Redelius, P (2003) Fatigue and healing characteristics of bitumens studied using dynamic shear rheometer. Paper presented at the 6th RILEM Symposium PTEBM'03, Zurich

9. Phillips MC (1998) Multi-step models for fatigue and healing, and binder properties involved in healing. Paper presented at the Eurobitume workshop on performance related properties for bituminous binders, Luxembourg

10. Pronk AC (2000) Partial healing model—curve fitting. Report WDWW-2000-047. DWW, Delft

11. Kim YR, Little DN, Lytton RL (2002) Use of dynamic mechanical analysis (DMA) to evaluate the fatigue and healing potential of asphalt binders in sand asphalt mixtures. J Assoc Asph Paving Technol 71:176-199

12. Bhasin A, Little DN, Bommavaram R, Vasconcelos K (2008) A framework to quantify the effect of healing in bituminous materials using material properties. Road Mater Pavement Des EATA 2008:219-242

13. Bommavaram R, Bhasin A, Little DN (2009) Determining intrinsic healing properties of asphalt binders: role of dynamic shear rheometer. Transp Res Rec 2126:47-54

14. Shan L, Tan Y, Underwood S, Kim YR (2010) Application of thixotropy to analyze fatigue and healing characteristics of asphalt binder. Paper presented at the 2010 annual meeting of the Transportation Research Board

15. Mo LT, Huurman M, Woldekidan MF, Wu SP, Molenaar AAA (2010) Investigation into material optimization and development for improved ravelling resistant porous asphalt concrete. Mater Des 31(7):3194-3206

16. Qiu J, Van de Ven MFC, Wu SP, Yu JY, Molenaar AAA (2009) Investigating the self healing capability of bituminous binders. Road Mater Pavement Des 10(SI):81-94

17. Qiu J, Van de Ven MFC, Wu SP, Yu JY, Molenaar AAA (2010) Asphalt pavements are self healing. Paper presented at the 1 st international conference on sustainable construction materials: design, performance and application. Wuhan, China

18. Qiu J (2008) Self healing of asphalt mixes: literature review. Report 7-08-183-1. Delft University of Technology, Delft

19. Majidzadeh K, Kauffmann EM, Ramsamooj DV (1971) Application of fracture mechanics in the analysis of pavement fatigue. J Assoc Asph Paving Technol 40:227-246 
20. Molenaar AAA (1983) Structural performance and design of flexible road constructions and asphalt concrete overlays. $\mathrm{PhD}$ thesis, Delft University of Technology, Delft

21. Majidzadeh K, Buranorom C, Karakouzian M (1976) Application of fracture mechanics for improved design of bituminous concrete. Report FHWA-RD-76-91, vol 1 and 2

22. Molenaar AAA, Heerkens JCP, Verhoeven JHM (1986) Effects of stress absorbing membrane interlayers. J Assoc Asph Paving Technol 55:453-481

23. Brown SF, Thom NH, Sanders PJ (2001) A study of grid reinforced asphalt to combat reflective cracking. J Assoc Asph Paving Technol 70:543-570

24. Rowe GM, Lewandowski LH, Grzybowski KF, Rasche J (2009) Development of the beam on elastic foundation for the evaluation of Geo-synthetic materials for reinforcing of asphalt layers. Paper presented at the 2009 annual meeting of the Transportation Research Board

25. Gaedicke C (2009) Fracture-based method to determine the flexural load capacity of concrete slabs. PhD thesis, University of Illinois, Urbana-Champaign
26. Roesler J, Gaedicke C (2009) Fracture-based method to determine the flexural load capacity of concrete slabs. Draft Final Report for Federal Aviation Administration. University of Illinois

27. Roesler J, Gaedicke C (2010) Flexural behavior of boncrete specimens on barious support conditions. Paper presented at the 7th international DUT-workshop on design and performance of sustainable and durable concrete pavements. Seville, Spain

28. Qiu J, Xuan D, van de Ven MFC, Molenaar AAA (2009) Evaluation of the shear box compactor as an alternative compactor for asphalt mixture beam specimens. Paper presented at the AES-ATEMA'2009, 3rd international conference on advances and trends in engineering materials and their applications. Montreal, Canada

29. Hordijk DA (1991) Local approach to fatigue of concrete. $\mathrm{PhD}$ thesis, Delft University of Technology, Delft 